\title{
Epidermal naevus syndrome: 2 cases with a rare triad
}

\author{
Jithangi Wanigasinghe ${ }^{1}$, Ranmali Rodrigo ${ }^{2}$, Pathum Dissanayake ${ }^{2}$
}

Sri Lanka Journal of Child Health, 2013; 41(1): 52-53

(Key words: Epidermal naevus syndrome; hemimegalencephaly; hemifacial lipoma; infantile spasms)

The term epidermal naevus syndrome (ENS) encompasses a group of disorders which in addition to epidermal naevi characteristically includes the presence of subcutaneous or adnexal lesions, sometimes with other organ involvement ${ }^{1}$. Triad of epidermal naevi, hemimegalencephaly and hemifacial lipoma is a rare association within the spectrum of ENS. We report two children with this combination of clinical features.

\section{Case 1}

Baby J, now 2 years old, has diffuse pigmentary mosaicism over left maxillary and mandibular regions and ipsilateral hemimegalencephaly on magnetic resonance imaging (MRI). Around four months of age, progressive enlargement of her left cheek was noted. Computed tomography revealed a lipomatous growth of cheek extending to neck causing deviation of upper airway to the right.

Her first presentation was with clusters of tonic seizures, highly refractory to treatment during the neonatal period. The tonic seizures and the electroencephalographic finding of burst suppression pattern supported a clinical diagnosis of Ohtohara syndrome. Around 3 months of age she developed epileptic spasms. By 6 months of age her right sided hemiplegia was clinically noticeable. The lipomatous lump showed a reduction in size during the second year of life. She is presently seizure free for more than 12 months but remains significantly delayed in her development globally.

\section{Case 2}

Master B has pigmentary mosaisicm over left face and right anterior trunk. This was initially faint but progressively enlarged in size and in pigmentation during the first year of life. Hemiplegia was noted opposite to the side of facial naevus. He has

${ }^{1}$ Senior Lecturer, ${ }^{2}$ Lecturer,
Paediatrics, Faculty of Medicine, Colombo

(Received on 2 May 2012: Accepted after revision on 15 June 2012) hemimegalencephaly of the left cerebrum and cerebellum. Progressive enlargement of the cheek on the side of facial naevus was noted from six month of age onwards.

His first presentation was at 2 months of age with right-sided focal seizures. Epileptic spasms developed around 12-14 months of age. The soft tissue enlargement continued to increase up to about 2 years of age followed by a slight regression in size. Currently at 30 months of age he has occasional focal seizures, an overall developmental age of around 15 months and right-sided hemiplegia.

\section{Discussion}

Epidermal naevus syndrome (ENS) is a group of disorders that is characterised by the presence of different types of epidermal naevi along with subcutaneous or adnexal lesions ${ }^{1}$. These naevi can range from simple pigmentary to sebaceous or even acanthotic or verrucous plaque lesions ${ }^{2}$. They are hamartomas that usually follow the lines of Blaschko and do not cross the midline ${ }^{3}$. They are present at birth or appear in the first year of life like in our two patients with change in appearance occurring with age.

Extracutaneous involvement, when present, is mainly in the form of central nervous system involvement; hence it is considered to be a neurocutaneous syndrome. Ocular, skeletal, genitourinary and cardiac systems may also be involved ${ }^{2}$.

The association of epidermal naevus, hemimegalencephaly and hemifacial lipoma was first described 50 years ago but only recently was the facial mass identified as a true lipoma. Unilateral lipomas often occur over the lower check.

Hemimegalencephaly per se is an uncommon association in neurocutaneous syndromes. Cerebellum being affected is even less frequent ${ }^{4,5}$. Co-occurrence of hemimegalencephaly and facial hemihypertrophy is a very rare condition ${ }^{6}$. 
In a case series of 60 patients who had ENS with neurological features a little over $25 \%$ had hemimegalencephaly. Less than half of these patients had hemiparesis and an even smaller number had ipsilateral facial hemihypertrophy ${ }^{5}$. As in our patients the hemifacial hypertrophy when present and the naevus are usually ipsilateral to the cerebral malformation ${ }^{5}$.

Epilepsy is almost invariable in those with hemimegalencephaly ${ }^{4}$ and often occurs early in life with the majority developing their first seizure before first 8 months. Several epilepsy syndromes are described including Ohtohara syndrome and infantile spasms, both of which may progress to Lennox Gastaut syndrome. Neither a molecular basis nor a heritable pattern has been described for this variety of ENS to date.

\section{References}

1. Sugarman JL. Epidermal naevus syndromes. Seminars in Cutaneous Medicine and Surgery 2007; 26: 221-30.

http://dx.doi.org/10.1016/j.sder.2008.03.006

2. Vujevich JJ, Mancini AJ. Case report - The epidermal naevus syndromes: Multisystem disorders. Journal of the American Academy of Dermatology 2004; 50: 957-61. http://dx.doi.org/10.1016/S0190-9622(02)61547-6
3. Brandling-Bennett HA, Morel KD. Epidermal naevi: Birthmarks of clinical significance. Pediatric Clinics of North America 2010; 57: 1177-98.

http://dx.doi.org/10.1016/j.pcl.2010.07.004

4. Flores-Sarnat L. Hemimegalencephaly: Part 1. Genetic, clinical and imaging aspects. Journal of Child Neurology 2002; 17:373-84. http://dx.doi.org/10.1177/088307380201700512

5. Pavone L, Curatolo P, Rizzo R, et al. Epidermal naevus syndrome: a neurologic variant with hemimegalencephaly, gyral malformation, mental retardation, seizures, and facial hemihypertrophy. Neurology 1991; 41: 266-71. http://dx.doi.org/10.1212/WNL.41.2_Part_1.266

6. Sakuta R, Aikawa H, Takashima $\mathrm{S}$ et al. Epidermal naevus syndrome with hemimegalencephaly: a clinical report of a case with acanthosis nigricans-like naevi on the face and neck, hemimegalencephaly, and hemihypertrophy of the body. Brain Development. 1989; 11(3):191-4. http://dx.doi.org/10.1016/S0387-7604(89)80097$\underline{X}$ 